\title{
Desindustrialização e investimento em tecnologia: a década de 1980 e seus reflexos nas décadas seguintes
}

\author{
Deindustrialization and investment in technology: \\ the 1980s and their reflexes in the following decades \\ Desindustrialización e inversión em tecnología: \\ la década de 1980 y sus consecuencias en las décadas siguientes \\ Daniel Wagner Haddad \\ Universidade Presbiteriana Mackenzie - SP - Brasil \\ Bolsista CAPES/PROSUC \\ ORCID: https://orcid.org/0000-0002-3585-2831 \\ Endereço Currículo Plataforma Lattes: http://lattes.cnpq.br/9202535828281007 \\ E-mail: daniel@danielwh.com
}

\begin{abstract}
Resumo: O presente artigo analisa a redução de investimentos em pesquisa, ciência e tecnologia na década de 1980 e seus reflexos nas décadas seguintes, especialmente com a falta de recuperação e retomada desses investimentos comparados à época da política desenvolvimentista, com grande repercussão na indústria, especialmente demonstrando falta de competitividade do Brasil tanto internamente, com a abertura do mercado no início dos anos 1990, como também no jogo internacional, persistindo tal defasagem até os dias atuais.
\end{abstract}

Palavras-chave: Pesquisa. Ciência. Tecnologia. Investimentos. Indústria. Política industrial.

\begin{abstract}
This article analyzes the reduction of investments in research, science and technology in the 1980s and their reflexes in the following decades, especially with the lack of recovery and resumption of these investments compared to the time of development policy, with great repercussion in the industry, especially demonstrating Brazil's lack of competitiveness both internally, with the opening of the market in the early 1990s, as well as in the international game, with such a lag persisting to the present day.
\end{abstract}

Keywords: Research. Science. Technology. Investments. Industry. Industrial policy.

Resumen: Este artículo analisa la reducción de las inversiones en investigación, ciencia y tecnología en la década de 1980 y sus consecuencias en las décadas siguientes, 
especialmente con la falta de recuperación y reanudación de estas inversiones en comparación con la era de la política de desarrollo, con gran repercusión en la industria, especialmente demostrando la falta de competitividad de Brasil tanto a nivel interno, con la apertura del mercado a principios de la década de 1990, como en el juego internacional, con tal brecha que persiste hasta el día de hoy.

Palabras-claves: Investigación. Ciencias. Tecnología. Inversiones. Industria. Política industrial.

\section{INTRODUÇÃO}

O ano de 1980 pode ser considerado como o ano do rompimento de um modelo que vinha sendo implementado desde 1930: o nacional-desenvolvimentismo. Observa-se que durante a década de 1980 houve uma mudança de rumo da política brasileira: ainda que sob os efeitos internacionais das crises do petróleo, do abandono do padrão-ouro pelos Estados Unidos da América com o aumento de suas taxas de juros que criou uma outra crise, da dívida externa em países em desenvolvimento, verifica-se que a escolha nacional foi principalmente tentar combater problemas internos como a hiperinflação e seguir a política de exportações a qualquer custo, de forma a manter a balança comercial positiva para o país. Entretanto, o crescimento industrial dependia de Investimento Estrangeiro Direto (IED) e uma necessidade estrutural de financiamento externo.

O fim do II Plano Nacional de Desenvolvimento (PND) coincide com o início da década de 1980, de modo que os megablocos de investimento cessaram ou foram postergados. Ocorre que, se o II PND objetivou completar o processo de substituição das importações deixando o país menos vulnerável aos choques externos, exatamente por buscar aumento da capacidade energética e privilegiar setores produtores de insumos básicos e bens de capital acabou deixando de lado segmentos da nova revolução tecnológica (microeletrônica) e não a aproximando do complexo metalmecânico-químico, aliado a isso o protecionismo que mantinham as indústrias nacionais locais isoladas da dinâmica externa.

Pegando-se como referência o setor de bens de capital, nas décadas de 1970 e 1980 difundiram-se internacionalmente novas máquinas e equipamentos que 
incorporaram dispositivos microeletrônicos, em uma grande mudança tecnológica do setor. A indústria nacional adentrou nesse novo paradigma ao longo da década de 1980 com grande defasagem temporal e com sérias restrições estruturais por conta de limites internos relacionados à capacitação tecnológica de empresas do setor.

Assim, o terreno que a década de 1980 iria florescer estava preparado. A indústria demonstrava elevados graus de integração intersetorial e de diversificação da produção, mas insuficiente desenvolvimento tecnológico, ineficiência técnica e ausência de qualquer padrão nítido de especialização. Evidentemente, em uma simples análise de competitividade da indústria nacional com a indústria internacional, algumas medidas, de forma muito clara, teriam que ser tomadas, principalmente no campo de pesquisa e desenvolvimento científico e tecnológico, para que o país pudesse entrar no jogo internacional com chances de competir.

Contudo, sabidamente, não foi o que ocorreu e os frutos (ou a falta deles) são colhidos (ou não) não apenas naquela década, mas também nas décadas seguintes. É também evidente que a defasagem industrial nacional está inserida em um contexto macroeconômico e de políticas econômicas tomadas ao longo das décadas. Entretanto, não se pode ignorar o papel de pesquisa, ciência e tecnologia, especialmente a redução de investimentos nesse setor.

\section{I- A Política Industrial e a diminuição dos gastos em Pesquisa e Desenvolvimento e em Ciência e Tecnologia}

Poder-se-ia justificar essa falta de investimentos com o desequilíbrio financeiro do setor público, principal financiador de Pesquisa e Desenvolvimento (P\&D) ou Ciência e Tecnologia (C\&T). A participação dos investimentos do governo federal em P\&D nos anos 1980 era na faixa de três quartos do total desses investimentos. Ao setor privado correspondia cerca de $8 \%$ do total de gastos. Desses gastos em P\&D, entre $45 \%$ e $50 \%$ eram direcionados ao desenvolvimento tecnológico industrial. Ocorre que a indústria era responsável por aproximadamente $35 \%$ do PIB, ou seja, a "densidade tecnológica" (relação entre a participação percentual do setor industrial nos gastos totais do país em C\&T) era baixíssima, tendo em vista no plano internacional as principais economias capitalistas direcionavam $90 \%$ desses gastos para a indústria, que gerava um terço do PIB. 
Levando-se em consideração os gastos em C\&T per capita a distância para as principais economias (G7) da época era ainda mais gritante: o Brasil gastava cerca de 4\% por habitante o que esses países gastavam, ou seja, de cada 100 dólares o que os países do G7 gastavam, o Brasil gastava 4 dólares.

Conforme identificou Wilson Suzigan"1, "A instabilidade macroeconômica afetou também o sistema de desenvolvimento científico e tecnológico, que sofreu corte de recursos orçamentários, redução ou fechamento de centros de P\&D (principalmente nas empresas estatais), perda de pessoal técnico, redução dos orçamentos de fundos específicos de financiamento a projetos de desenvolvimento científico e tecnológico, e cortes de bolsas de pesquisa e pós-graduação. A questão que se coloca é: que desenvolvimento industrial é possível com o que resta do sistema de desenvolvimento científico e tecnológico?”.

Em Schumpeter encontra-se o pioneirismo na análise do desenvolvimento do progresso técnico e seus efeitos na economia. Desenvolveu de forma clara a ideia de um sistema econômico cuja principal característica de evolução residia no incessante processo de inovação. Na evolução de sua teoria, Schumpeter afirma que o desenvolvimento econômico deve ultrapassar as fronteiras do eventual, para se tornar um processo dinâmico, evolutivo e, acima de tudo, destruidor. Segundo o próprio Schumpeter, passa haver um "processo de mutação industrial - se é que podemos usar esse termo biológico, que revoluciona a estrutura econômica a partir de dentro, destruindo incessantemente o antigo e criando elementos novos. É dele que se constitui o capitalismo e a ele deve se adaptar toda a empresa capitalista para sobreviver" 2 .

Assim, destacam Andre Carraro e Pedro Cezar Dutra Fonseca ${ }^{3}$, "a organização da produção, a combinação de novos insumos e a busca constante por novos produtos passam a ser fundamentais para geração de desenvolvimento econômico. Estas seriam funções próprias não exclusivamente do empresário inovador, mas de uma rede de órgãos e instituições que seriam criadas com o

\footnotetext{
1 Vide o ensaio "Industrialização brasileira em perspectiva", extraído de http://www.abphe.org.br/arquivos/wilson-suzigan.pdf.

${ }^{2}$ Conforme SCHUMPETER, Capitalism, Socialism and Democracy. London: Geroge Allen and Unwin, 1942, extraído de "O Desenvolvimento Econômico no Primeiro Governo de Vargas (1930-1945)"; André Carraro e Pedro Cezar Dutra Fonseca, p.8.

${ }^{3}$ Idem, p. 8

DOI: http://doi.org/10.14393/par-v6n1-2021-58547 - Paradoxos, Uberlândia, v. 6, n. 1, p. 6-20, jan./jun. 2021| 9
} 
objetivo principal de inserir no sistema econômico os incentivos necessários para que as empresas se lançassem continuamente na busca do novo, do desenvolvimento, não por decisões pessoais, mas por questão de sobrevivência. Neste momento, surge na visão schumpeteriana de desenvolvimento econômico um dos importantes papéis assumidos pelo Estado: a criação de órgãos e institutos que incentivem o investimento industrial ao contribuir com a indústria privada na tarefa de planejar, estimular e promover de forma organizada o desenvolvimento econômico nacional".

A defasagem tecnológica do Brasil no jogo industrial internacional o fez buscar espaço em outros setores, notadamente na exportação de commodities e um aumento expressivo no setor de serviços, conforme se observa na retração da industrialização nas décadas seguintes, contrariando as seis décadas anteriores de política desenvolvimentista. Sem forças para se destacar no campo industrial, o país foi sendo ultrapassado e perdendo espaço no campo da indústria, que consequentemente representou baixos índices de crescimento.

Por isso, se se observa uma fase de catching-up tecnológico no Brasil até 1980, emparelhando-se com países mais desenvolvidos, a partir desse ano se observa um falling behind tecnológico, com o país ficando atrás tecnologicamente. Na verdade, a fase de catching-up seguiu uma estratégia de industrialização baseada em recursos externos, que se demonstrou vulnerável, por conta de desgastadas e superadas estratégias de industrialização, iniciando-se essa nova fase de falling behind.

Assim, afirma Suzigan e Furtado (2006), em vez de uma mudança houve, de 1981 em diante, uma reversão do processo histórico com involução de tecnologias, de estruturas empresariais e industriais e de instituições lato senso, isto é, inclusive políticas, e com deterioração das infra-estruturas e abandono do SNDCT.

Daí surge a importância de uma "Política Industrial" de modo a fomentar os setores de pesquisa, ciência e tecnologia, que levam à inovação e poder de competitividade industrial. Por Política Industrial (PI) pode ser considerada uma forma de planejamento e construção de estratégias de desenvolvimento, devendo ser compatibilizadas com as políticas macroeconômicas, abrangendo políticas de proteção e fomento da indústria nascente, políticas comerciais setoriais, incentivo à ciência e tecnologia, regulação de Investimento Estrangeiro Direto, direitos de propriedade 
intelectual, dentre outras medidas que podem ser adotadas. Dependem, portanto, de liderança política e coordenação ${ }^{4}$, do setor público com o setor privado.

Assim, pode-se ter a Política Industrial não apenas como instrumento de correção de falhas do mercado, mas também como ênfase na qualificação de mão de obra, aumento da eficiência do uso de recursos, acesso facilitado a financiamento das atividades, coordenação estratégica, etc. Desse modo, a atuação da Política Industrial de modo a fomentar a pesquisa, ciência e tecnologia se faz necessária.

Ressalte-se o que já foi destacado no início do texto, com relação a questão macroeconômica influenciando a Política Industrial. Evidentemente, tudo deve ser somado para entender a questão industrial brasileira, passando obviamente, pela hipótese levantada de baixo investimento em tecnologia resultar em baixo desenvolvimento industrial e baixíssima competitividade no jogo internacional. Some-se a esse fato a proteção à indústria nacional, com o fechamento do mercado para a proteção interna. Desse modo, identificou Antonio Barros de Castro ${ }^{5}$, que

$\mathrm{Na}$ raiz do problema encontra-se uma insuficiência herdada do período de proteção e alta inflação. Não se tratava de baixa capacitação para produzir, como pretendiam os críticos do chamado modelo de substituição de importações. O problema consistia em que a proteção e a alta inflação permitiam que os produtores pouco esforço fizessem para conquistar os consumidores. Não era preciso ir atrás do peixe: ele próprio entrava na rede. Isto prosseguiu durante toda a alta inflação - e não chegou a ser superado, mesmo com a reestruturação detonada pela abertura. Afinal, para disputar o mercado doméstico, mostrou-se suficiente oferecer artigos similares aos importados, a preços competitivos. Numa palavra, os produtores locais em grande medida continuavam despreparados para disputar mercados com as modernas armas da competição: não vendem, são comprados, na expressão cunhada por produtores gaúchos de calçados.

Por esse ângulo, verifica-se que o contingenciamento e pouco investimento em pesquisa, ciência e tecnologia sequer era algo almejado pela indústria nacional, que não via necessidade de aumentar sua produtividade e tecnologias de seus produtos diante do protecionismo existente no mercado interno.

\footnotetext{
${ }^{4}$ Nesse sentido vide SUZIGAN e FURTADO, 2006, p. 165/169.

${ }^{5}$ CASTRO, Antonio Barros de. A Rica Fauna da Política Industrial e a sua Nova Fronteira. 


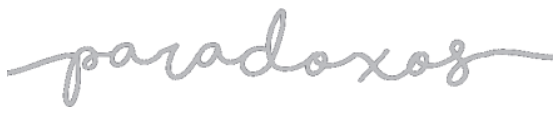

Desindustrialização e

investimento em tecnologia: a década de 1980 e seus reflexos nas décadas seguintes

HADDAD, 2021

\section{II - A industrialização tardia}

Interessante comparação se faz do Brasil com a Coreia do Sul ${ }^{6}$, ambos países de industrialização tardia. Apesar de sua pequena dimensão territorial, o país asiático possui população comparável, por exemplo, à das principais economias europeias e superior à da Argentina, que são inevitavelmente tomadas como critérios de comparação. Ambos os países, em seu processo de desenvolvimento, possuem elementos para se enquadrarem na perspectiva desenvolvimentista. Evidentemente, as regiões em que os países estão situados influenciaram a economia e a própria industrialização. Comparando os esforços do Leste Asiático com a América Latina, no campo de $\mathrm{P} \& \mathrm{D}$, por exemplo, foi verificado um rápido crescimento de atividades técnicas e científicas à nível empresarial nos países do Leste Asiático, enquanto nos países da América Latina um crescimento lento, estagnação ou até mesmo queda no nível empresarial em P\&D e outras atividades de aprendizado.

Atualmente a Coreia do Sul possui duas marcas de automóveis globais, enquanto o Brasil sofre para manter suas plantas industriais do setor ativas, convivendo com fechamentos dessas plantas ou recebimento de incentivos fiscais para que essas plantas não fechem ou venham outras montadoras (inclusive coreanas) para ocupar o espaço deixado por outras que não possuem mais interesse no país. Como reflexo dessa política estatal de industrialização, com investimentos maciços em $\mathrm{C} \& \mathrm{~T}$, a renda per capita da Coreia do Sul em 1980 era de US\$ 3.910,77 saltando para US\$24.479,24 em 2013. No Brasil, a renda per capitai em 1980 era muito superior à coreana, de US\$ 8.246,45, indo para US\$ 11.705,43 no ano de 2013.

Não apenas os índices econômicos e de renda coreanos melhoraram muito, principalmente comparando com a perspectiva brasileira, que à época tinha números melhores em praticamente todos os índices econômicos, mas os índices de produção em pesquisa foram proporcionais a esse salto econômico.

A produção científica coreana, pegando como ano de comparação o ano de 1985, era de $0,12 \%$ no total de publicações científicas e técnicas indexadas pelo SCI

\footnotetext{
${ }^{6}$ Vide a dissertação de mestrado de PRIZON, Ivan. Sistemas de inovação e a mudança econômica nos países de industrialização tardia: uma comparação dos esforços e desempenhos de Brasil e Coreia do Sul. Universidade Federal de Santa Maria, 2017.
}

DOI: http://doi.org/10.14393/par-v6n1-2021-58547 - Paradoxos, Uberlândia, v. 6, n. 1, p. 6-20, jan./jun. $2021 \mid 12$ 
e pelo SSCI, em face de uma participação brasileira de 0,41\%. Em 2013, esse número era de 2,23\% para as publicações brasileiras e 2,69\% para as publicações sul-coreanas. Ocorre que, pegando os números que demonstram a prática da pesquisa, o registro de patentes, tem-se uma enorme evolução dos registros coreanos a partir do final da década de 1980 e começo da década de 1990, exatamente no período "perdido" brasileiro, resultando em 2015 que 6,01\% do total mundial de registros era coreano contra $0,11 \%$ de registros brasileiros.

Inevitavelmente, a comparação entre os países demonstra a importância do investimento em pesquisa, ciência e tecnologia, como fundamentais para a Política Industrial e também para o desenvolvimento econômico do país.

\section{III- A entrada na década de 1990 e a desindustrialização nas décadas seguintes}

Voltando ao caso brasileiro, esse baixo investimento em C\&T fez o país adentrar na década de 1990 sem que a indústria pudesse competir com a nova política de abertura e liberalismo que se impôs. A indústria estava defasada para competir tanto internamente, com a abertura que se apresentou, quanto internacionalmente, pela própria fragilidade e baixo poder de inovação.

A década de 1990 com sua política de liberalização das importações não foi acompanhada de um planejamento de política industrial, o que refletiu na enorme dificuldade da indústria até mesmo de aproveitar-se desse liberalismo das importações e trazer insumos para suas atividades, tendo em vista que as "peças" trazidas de fora não “encaixariam" no defasado cenário industrial que se apresentava.

Foi identificado como um dos pontos fracos na política que se adotava no início da década de 1990, exatamente a defasagem tecnológica, com poucas iniciativas de P\&D, conforme destacou Flavio Tavares de Lyra7, "Desde logo, cabe destacar como resultados modestos da nova política os alcançados no campo da capacitação tecnológica, em que ainda foram poucas as iniciativas para a realização de projetos de $\mathrm{P} \& \mathrm{D}$, e baixos os investimentos na infra-estrutura tecnológica; nesse último caso, face à escassez de recursos públicos".

\footnotetext{
7 “A Política Industrial Brasileira: Mudanças e Perspectivas”. IPEA. Texto para discussão. N. 413. Maio 1996. DOI: http://doi.org/10.14393/par-v6n1-2021-58547 - Paradoxos, Uberlândia, v. 6, n. 1, p. 6-20, jan./jun. 2021| 13
} 
Uma visão muito clara do assunto é extraída de Wilson Suzigan:

Embora reconhecidamente necessária, a abertura comercial é limitada como instrumento indutor de mudanças capazes de redinamizar a indústria, modernizar sua estrutura produtiva, capacitá-la tecnologicamente e torná-la competitiva tanto no mercado interno quanto no mercado internacional. Essa limitação decorre do fato de não estar ancorada num conjunto de políticas e instrumentos articulados e sincronizados em torno de uma estratégia industrial. Além disso, pode ter efeitos regressivos sobre a estrutura da indústria por ser implementada simultaneamente a uma política macroeconômica recessiva, sem que mecanismos compensatórios — à Ia Corden (1980) — sejam aplicados.

Discorrendo sobre os setores de tecnologia avançada, demasiadamente afetados pela política de abertura e liberalização, SUZIGAN (1993) afirma que "são essenciais, e constitui prática universal, a proteção â empresa inovadora (geralmente nacional) e o apoio do Estado através de financiamento, incentivos fiscais para $\mathrm{P} \& \mathrm{D}$ e criação de condições favoráveis (sistema de C\&T, pesquisa e pós-graduação etc), o que não se verifica na atual política industrial brasileira".

Nos anos 2000 a realidade pouco mudou. A figura a seguir demonstra a estagnação nos investimentos, o que fez manter o Brasil em uma posição praticamente irrecuperável no jogo internacional, em uma época em que desenvolveu-se a grande revolução tecnológica, partindo da internet de alta velocidade, nanotecnologia, mobilidade da informação, novas redes de comunicação, automação industrial, novas formas de industrialização, novas fontes de energia eficientes, dentre diversas novidades no campo industrial verificadas em vários países desenvolvidos.

\footnotetext{
${ }^{8}$ Política comercial e perspectivas da indústria brasileira. Revista Indicadores Econômicos, Porto Alegre, v. 20, n.4, 1993, p. 121-133.
} 
Figura 1: investimentos nacionais em P\&D - de 2000 a $2010^{9}$

\section{Em 10 anos, investimentos nacionais em P\&D praticamente se mantêm estáveis}

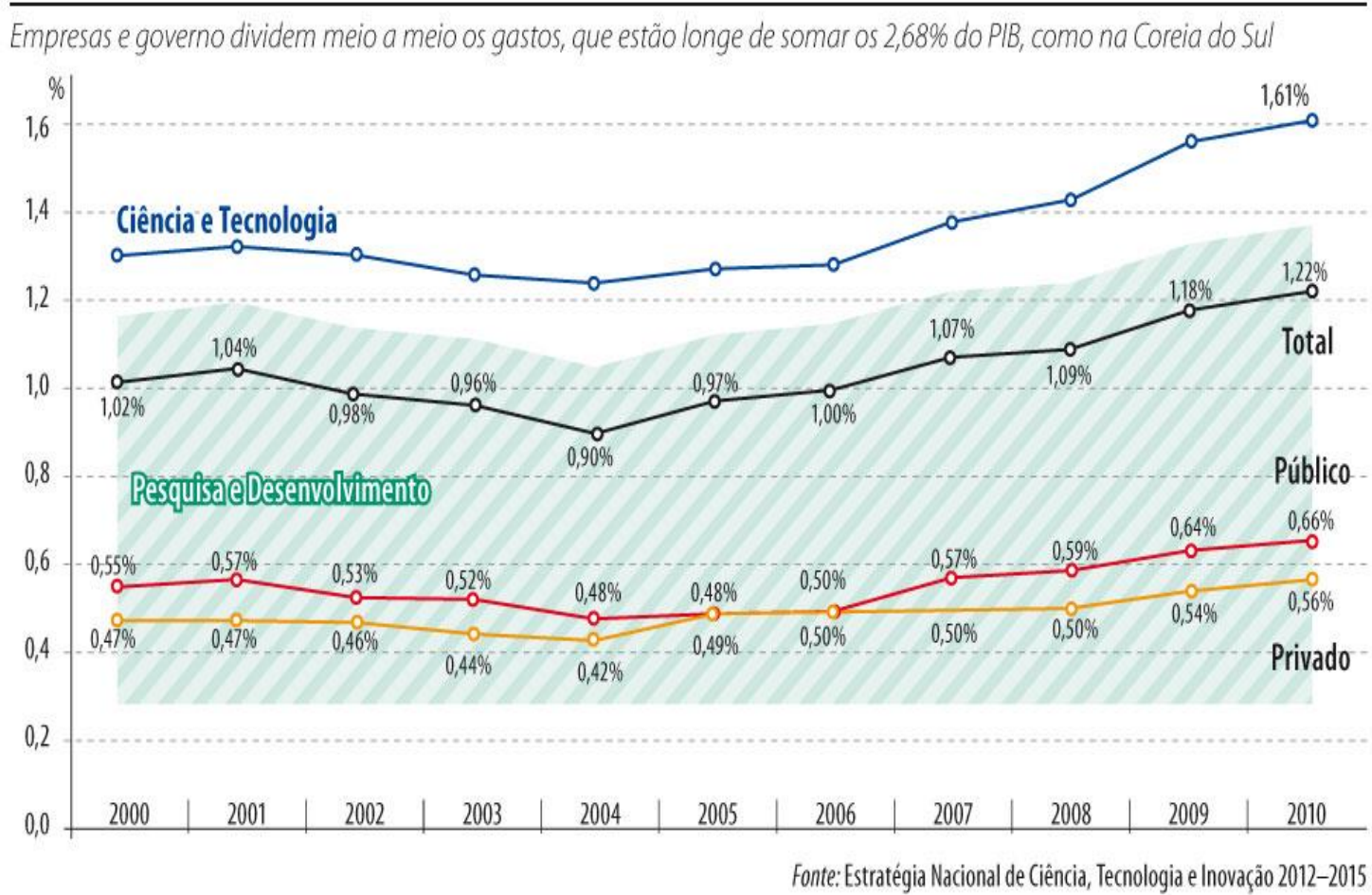

A situação nos anos seguintes também pouco mudou. Apesar de um tímido crescimento, conforme mencionado alhures, o falling behind tecnológico do Brasil ocasionado na década de 1980 exigiria um maior investimento como forma de recuperar a(s) década(s) perdida(s).

Verifica-se que, em valores absolutos, até houve uma melhora nos investimentos nos últimos anos, porém, em proporção do PIB, tal aumento acaba sendo tímido, insuficiente para transformar em uma melhora real para a indústria e para os produtos nacionais, ou seja, longe de ser uma Política Industrial.

\footnotetext{
${ }^{9}$ https://www.senado.gov.br/NOTICIAS/JORNAL/EMDISCUSSAO/inovacao/ciencia-tecnologia-einovacao-no-brasil.aspx. 
Figura 2: Dispêndio nacional em pesquisa e desenvolvimento (P\&D), em valores correntes, em relação ao total de P\&D e ao produto interno bruto (PIB), por setor institucional, 2000-2017 ${ }^{10}$

\begin{tabular}{|c|c|c|c|c|c|c|c|c|c|c|c|c|c|c|c|c|c|c|}
\hline \multirow{2}{*}{ Setores } & \multicolumn{18}{|c|}{ Valores correntes em milhões de RS } \\
\hline & 2000 & 2001 & 2002 & 2003 & 2004 & 2005 & 2006 & 2007 & 2008 & 2009 & 2010 & 2011 & 2012 & 2013 & 2014 & 2015 & 2016 & $2017^{(5)}$ \\
\hline otal & $12.560,7$ & $13.973,0$ & $15.031,9$ & $17.169,0$ & $18.861,6$ & $21.759,3$ & $23.807,0$ & $29.416,4$ & $35.110,8$ & $37.285,3$ & $45.072,9$ & $49.875,9$ & $54.254,6$ & $63.748,6$ & $73.468,2$ & $80.501,8$ & $79.228,3$ & $82.792,2$ \\
\hline Dispêndios públicos & $6.493,8$ & $7.447,8$ & $7.760,9$ & $8.826,0$ & $9.335,3$ & $10.371,2$ & $11.911,1$ & $15.184,8$ & $\begin{array}{ll}317.680,7 \\
\end{array}$ & $19.498,1$ & $23.039,2$ & $26.382,6$ & $29.802,9$ & $36.783,7$ & $38.823,3$ & $42.051,6$ & $41.499,8$ & $41.168,1$ \\
\hline Dispêndios federais ${ }^{(1)}$ & $4.007,7$ & $4.563,4$ & $4.828,3$ & $5.802,4$ & $6.418,3$ & $7.085,2$ & $8.483,5$ & $10.444,8$ & $12.069,1$ & $13.461,9$ & $16.039,5$ & $17.784,2$ & $20.020,7$ & $25.802,5$ & $26.102,1$ & $27.219,8$ & $26.592,2$ & $25.711,2$ \\
\hline Orçamento executado & $2.484,3$ & $2.973,0$ & $2.966,9$ & $3.643,2$ & $3.875,4$ & 4.4 & $5.164,0$ & $6.052,9$ & $7.035,9$ & $8.411,3$ & $9.969,7$ & $10.653,3$ & $12.013,9$ & $16.080,8$ & $14.941,4$ & $17.183,8$ & $14.636,7$ & $13.659,9$ \\
\hline Pós-graduação & $1.523,4$ & $1.590,4$ & $1.861,4$ & $2.159,3$ & $2.542,9$ & $2.616,1$ & $3.319,5$ & $4.391,9$ & $5.033,1$ & $5.050,7$ & $6.069,8$ & $7.130,9$ & $8.006,8$ & $9.721,7$ & $11.160,7$ & $10.036,0$ & $11.955,6$ & $12.051,3$ \\
\hline Dispêndios estaduais ${ }^{(2)}$ & $2.486,2$ & $2.884,4$ & $2.932,6$ & $3.023,6$ & $2.917,0$ & $3.286,1$ & $3.427,6$ & $4.740,1$ & $5.611,7$ & $6.036,2$ & $6.999,7$ & $8.598,4$ & $9.782,2$ & $10.981,3$ & $12.721,2$ & $14.831,8$ & $14.907,6$ & $15.456,9$ \\
\hline Orçamento executado & 941,8 & $1.125,4$ & 961,3 & 25,2 & $1.067,3$ & $1.320,8$ & $1.426,0$ & $1.717,2$ & $2.011,4$ & $2.321,1$ & $2.491,7$ & $2.767,9$ & $3.165,4$ & $3.345,8$ & $3.713,0$ & $4.259,1$ & $3.613,3$ & $3.662,5$ \\
\hline Pós-graduação & $1.544,4$ & $1.758,9$ & $1.971,3$ & $2.098,4$ & $1.849,7$ & $1.965,3$ & $2.001,6$ & $3.022,9$ & $3.600,3$ & $3.715,1$ & $4.508,0$ & $5.830,5$ & $6.616,8$ & $7.635,5$ & $9.008,1$ & $10.572,7$ & $11.294,2$ & $11.794,4$ \\
\hline Dispêndios empresariais & $6.066,8$ & $6.525,2$ & $7.271,0$ & $8.343,0$ & $9.526,3$ & $11.388,1$ & $11.895,9$ & $14.231,5$ & $17.430,1$ & $17.787,2$ & $22.033,6$ & $23.493,2$ & $24.451,7$ & $26.964,9$ & $34.644,9$ & $38.450,1$ & $37.728,5$ & $41.624,0$ \\
\hline Empresas privadas e estatais ${ }^{(3)}$ & $5.923,2$ & $6.345,9$ & $7.029,1$ & $8.022,0$ & $9.166,7$ & $10.974,5$ & $11.428,3$ & $13.560,9$ & $16.683,5$ & $16.980,7$ & $21.201,2$ & $22.560,3$ & $23.368,4$ & $25.722,4$ & $33.043,1$ & $36.665,4$ & $35.687,6$ & $39.296,9$ \\
\hline Pós-graduação( & 143,6 & 179,3 & 241,9 & 321,0 & 359,6 & 413,6 & 467,6 & 670,7 & 746,6 & 806,5 & 832,4 & 932,9 & $1.083,4$ & $1.242,5$ & $1.601,9$ & $1.784,8$ & $2.040,8$ & $2.327,1$ \\
\hline
\end{tabular}

\begin{tabular}{|c|c|c|c|c|c|c|c|c|c|c|c|c|c|c|c|c|c|c|}
\hline \multirow{2}{*}{ Setores } & \multicolumn{18}{|c|}{ \% em relaçăo ao total de P\&D } \\
\hline & 2000 & 2001 & 2002 & 2003 & 2004 & 2005 & 2006 & 2007 & 2008 & 2009 & 2010 & 2011 & 2012 & 2013 & 2014 & 2015 & 2016 & $2017^{(5)}$ \\
\hline Total & 100,00 & 100,00 & 100,00 & 100,00 & 100,00 & 100,00 & 100,00 & 100,00 & 100,00 & 100,00 & 100,00 & 100,00 & 100,00 & 100,00 & 100,00 & 100,00 & 100,00 & 100,00 \\
\hline Dispêndios públicos & 51,70 & 53,30 & 51,63 & 51,41 & 49,49 & 47,66 & 50,03 & 51,62 & 50,36 & 52,29 & 51,12 & 52,90 & 54,93 & 57,70 & 52,84 & 52,24 & 52,38 & 49,72 \\
\hline Dispêndios federais ${ }^{(1)}$ & 31,91 & 32,66 & 32,12 & 33,80 & 34,03 & 32,56 & 35,63 & 35,51 & 34,37 & 36,11 & 35,59 & 35,66 & 36,90 & 40,48 & 35,53 & 33,81 & 33,56 & 31,06 \\
\hline Orçamento executado & 19,78 & 21,28 & 19,74 & 21,22 & 20,55 & 20,54 & 21,69 & 20,58 & 20,04 & 22,56 & 22,12 & 21,36 & 22,14 & 25,23 & 20,34 & 21,35 & 18,47 & 16,50 \\
\hline Pós-graduação & 12,13 & 11,38 & 12,38 & 12,58 & 13,48 & 12,02 & 13,94 & 14,93 & 14,34 & 13,55 & 13,47 & 14,30 & 14,76 & 15,25 & 15,19 & 12,47 & 15,09 & 14,56 \\
\hline Dispêndios estaduais (2) & 19,79 & 20,64 & 19,51 & 17,61 & 15,47 & 15,10 & 14,40 & 16,11 & 15,98 & 16,19 & 15,53 & 17,24 & 18,03 & 17,23 & 17,32 & 18,42 & 18,82 & 18,67 \\
\hline Orçamento executado & 7,50 & 8,05 & 6,40 & 5,39 & 5,66 & 6,07 & 5,99 & 5,84 & 5,73 & 6,23 & 5,53 & 5,55 & 5,83 & 5,25 & 5,05 & 5,29 & 4,56 & 4,42 \\
\hline Pós-graduação & 12,30 & 12,59 & 13,11 & 12,22 & 9,81 & 9,03 & 8,41 & 10,28 & 10,25 & 9,96 & 10,00 & 11,69 & 12,20 & 11,98 & 12,26 & 13,13 & 14,26 & 14,25 \\
\hline Dispêndios empresariais & 48,30 & 46,70 & 48,37 & 48,59 & 50,51 & 52,34 & 49,97 & 48,38 & 49,64 & 47,71 & 48,88 & 47,10 & 45,07 & 42,30 & 47,16 & 47,76 & 47,62 & 50,28 \\
\hline Empresas privadas e estatais $^{(3)}$ & 47,16 & 45,42 & 46,76 & 46,72 & 48,60 & 50,44 & 48,00 & 46,10 & 47,52 & 45,54 & 47,04 & 45,23 & 43,07 & 40,35 & 44,98 & 45,55 & 45,04 & 47,46 \\
\hline Pós-graduaçãa $0^{(4)}$ & 1,14 & 1,28 & 1,61 & 1,87 & 1,91 & 1,90 & 1,96 & 2,28 & 2,13 & 2,16 & 1,85 & 1,87 & 2,00 & 1,95 & 2,18 & 2,22 & 2,58 & 2,81 \\
\hline
\end{tabular}

\begin{tabular}{|c|c|c|c|c|c|c|c|c|c|c|c|c|c|c|c|c|c|c|}
\hline \multirow{2}{*}{ Setores } & \multicolumn{18}{|c|}{ \%em relaçâo ao PIB } \\
\hline & 2000 & 2001 & 2002 & 2003 & 2004 & 2005 & 2006 & 2007 & 2008 & 2009 & 2010 & 2011 & 2012 & 2013 & 2014 & 2015 & 2016 & $2017^{(5)}$ \\
\hline Total & 1,05 & 1,06 & 1,01 & 1,00 & 0,96 & 1,00 & 0,99 & 1,08 & 1,13 & 1,12 & 1,16 & 1,14 & 1,13 & 1,20 & 1,27 & 1,34 & 1,26 & 1,26 \\
\hline Dispêndios públicos & 0,54 & 0,57 & 0,52 & 0,51 & 0,48 & 0,48 & 0,49 & 0,56 & 0,57 & 0,58 & 0,59 & 0,60 & 0,62 & 0,69 & 0,67 & 0,70 & 0,66 & 0,63 \\
\hline Dispêndios federais $^{(1)}$ & 0,33 & 0,35 & 0,32 & 0,34 & 0,33 & 0,33 & 0,35 & 0,38 & 0,39 & 0,40 & 0,41 & 0,41 & 0,42 & 0,48 & 0,45 & 0,45 & 0,42 & 0,39 \\
\hline Orçamento executado & 0,21 & 0,23 & 0,20 & 0,21 & 0,20 & 0,21 & 0,21 & 0,22 & 0,23 & 0,25 & 0,26 & 0,24 & 0,25 & 0,30 & 0,26 & 0,29 & 0,23 & 0,21 \\
\hline Pós-graduaç̃̃o & 0,13 & 0,12 & 0,13 & 0,13 & 0,13 & 0,12 & 0,14 & 0,16 & 0,16 & 0,15 & 0,16 & 0,16 & 0,17 & 0,18 & 0,19 & 0,17 & 0,19 & 0,18 \\
\hline Dispêndios estaduais ${ }^{(2)}$ & 0,21 & 0,22 & 0,20 & 0,18 & 0,15 & 0,15 & 0,14 & 0,17 & 0,18 & 0,18 & 0,18 & 0,20 & 0,20 & 0,21 & 0,22 & 0,25 & 0,24 & 0,24 \\
\hline Orçamento executado & 0,08 & 0,09 & 0,06 & 0,05 & 0,05 & 0,06 & 0,06 & 0,06 & 0,06 & 0,07 & 0,06 & 0,06 & 0,07 & 0,06 & 0,06 & 0,07 & 0,06 & 0,06 \\
\hline Pós-graduação & 0,13 & 0,13 & 0,13 & 0,12 & 0,09 & 0,09 & 0,08 & 0,11 & 0,12 & 0,11 & 0,12 & 0,13 & 0,14 & 0,14 & 0,16 & 0,18 & 0,18 & 0,18 \\
\hline Dispêndios empresariais & 0,51 & 0,50 & 0,49 & 0,49 & 0,49 & 0,52 & 0,49 & 0,52 & 0,56 & 0,53 & 0,57 & 0,54 & 0,51 & 0,51 & 0,60 & 0,64 & 0,60 & 0,64 \\
\hline Empresas privadas e estatais $^{(3)}$ & 0,49 & 0,48 & 0,47 & 0,47 & 0,47 & 0,51 & 0,47 & 0,50 & 0,54 & 0,51 & 0,55 & 0,52 & 0,49 & 0,48 & 0,57 & 0,61 & 0,57 & 0,60 \\
\hline Pós-graduação( ${ }^{(4)}$ & 0,01 & 0,01 & 0,02 & 0,02 & 0,02 & 0,02 & 0,02 & 0,02 & 0,02 & 0,02 & 0,02 & 0,02 & 0,02 & 0,02 & 0,03 & 0,03 & 0,03 & 0,04 \\
\hline
\end{tabular}

Um baixo grau de industrialização fez o país terminar o ano de 2018 com a participação da indústria de transformação no Produto Interno Bruto (PIB) em 11,3\%, a menor desde 1947 e iniciar o ano de 2019 ainda pior, com participação de 10,4\% ${ }^{11}$. A questão que se coloca é que um país com baixa industrialização possui pouco crescimento econômico. A pergunta que deve ser feita é, portanto, como fazer não apenas o país crescer, mas crescer com "sobras" para recuperar o que fora perdido, sem uma política industrial?

\footnotetext{
${ }^{10} \mathrm{http} / / /$ www.mctic.gov.br/mctic/opencms/indicadores/detalhe/recursos_aplicados/indicadores consolidad os/2 $13 . \mathrm{html}$.

${ }^{11}$ https://www1.folha.uol.com.br/mercado/2019/05/peso-da-industria-no-pib-cai-ao-menor-nivel-da-serie.shtml. DOI: http://doi.org/10.14393/par-v6n1-2021-58547 - Paradoxos, Uberlândia, v. 6, n. 1, p. 6-20, jan./jun. 2021| 16
} 
Apesar das várias correntes conflitantes, pode-se afirmar que o país passa por um processo de desindustrialização, sendo uma das causas da perda de protagonismo da indústria a defasagem nacional em ciência e tecnologia.

Assim, conforme se extrai de José Luis Oreiro e Carmem A. Feijó ${ }^{12}$, sobre o conceito de desindustrialização,

Tregenna (2009) redefiniu de forma mais ampla o conceito "clássico" de desindustrialização como sendo uma situação na qual tanto o emprego industrial como o valor adicionado da indústria se reduzem como proporção do emprego total e do PIB, respectivamente.

A primeira observação importante a respeito do conceito ampliado de "desindustrialização" é que o mesmo é compatível com um crescimento (expressivo) da produção da indústria em termos físicos. Em outras palavras, uma economia não se desindustrializa quando a produção industrial está estagnada ou em queda, mas quando o setor industrial perde importância como fonte geradora de empregos e/ou de valor adicionado para uma determinada economia. Dessa forma, a simples expansão da produção industrial (em termos de quantum) não pode ser utilizada como "prova" da inexistência de desindustrialização.

A segunda observação é que a desindustrialização não está necessariamente associada a uma "re-primarização da pauta de exportação". Com efeito, a participação da indústria no emprego e no valor adicionado pode se reduzir em função da transferência para o exterior das atividades manufatureiras mais intensivas em trabalho e/ou com menor valor adicionado. Se assim for, a desindustrialização pode vir acompanhada por um aumento da participação de produtos com maior conteúdo tecnológico e maior valor adicionado na pauta de exportações. Nesse caso, a desindustrialização é classificada como "positiva". No entanto, se a desindustrialização vier acompanhada de uma "re-primarização" da pauta de exportações, ou seja, por um processo de reversão da pauta exportadora na direção de commodities, produtos primários ou manufaturas com baixo valor adicionado e/ou baixo conteúdo tecnológico; então isso pode ser sintoma da ocorrência de "doença holandesa", ou seja, a desindustrialização causada pela apreciação da taxa real de câmbio resultante da descoberta de recursos naturais escassos num determinado país ou região. Nesse caso, a desindustrialização é classificada como "negativa", pois é o resultado de uma "falha de mercado" na qual a existência e/ou a descoberta de recursos naturais escassos, para os quais o preço de mercado é superior ao custo marginal social de produção, gera uma apreciação da taxa de câmbio real, produzindo assim uma externalidade negativa sobre $o$ setor produtor de bens manufaturados (Bresser-Pereira, 2008).

${ }^{12}$ OREIRO, José Luis; FEIJO, Carmem A.. Desindustrialização: conceituação, causas, efeitos e o caso brasileiro. Rev. Econ. Polit., São Paulo, v. 30, n. 2, p. 219-232. 
Inclusive nesse ponto, de retomada de uma primarização da pauta de exportações, o abismo tecnológico brasileiro o obrigou a retomar uma pauta exportadora baseada em produtos de baixo conteúdo tecnológico e valor agregado.

\section{CONCLUSÃO}

Ao que parece, com previsões da participação da indústria no PIB cair à casa de um dígito no ano de 2020, e com o evidente movimento de retorno ao campo, com a supervalorização das commodities, há o risco de em algumas décadas ser substituída a expressão "década perdida" por "século perdido" para a indústria nacional, regressando aos tempos "pré-desenvolvimentismo". Ocorre que, sem uma indústria com forte participação no PIB, não há crescimento.

A falta de maiores investimentos em pesquisa, ciência e tecnologia - repitase, não apenas para manter o padrão brasileiro atual com o dos países desenvolvidos, mas recuperar o tempo perdido das últimas décadas - faz com que o Brasil aumente sua dependência de tecnologias internacionais. Com o lançamento iminente da tecnologia 5G, por exemplo, não há caminho ao país senão aderir a um projeto tecnológico estrangeiro, chinês ou estadunidense por exemplo, como forma de utilizar o atraso como vantagem (ou seja, não ter que desenvolver durante anos uma tecnologia própria) e a partir daí alavancar os investimentos para competir de igual no jogo internacional.

\section{REFERÊNCIAS}

AREND, Marcelo. 50 anos de industrialização no Brasil (1955-2005): uma análise evolucionária. Tese de Doutorado em Economia UFRGS. Disponível em: https://www.lume.ufrgs.br/bitstream/handle/10183/16408/000697917.pdf?sequence=1\& isAllowed=y. Acesso em 14 de outubro de 2019.

CARRARO, Andre e FONSECA, Pedro Cezar Dutra. O Desenvolvimento Econômico no Primeiro Governo de Vargas (1930-1945). Publicado nos Anais do V Congresso 
Brasileiro de História Econômica e $6^{\text {a }}$ Conferência Internacional de História de Empresas, Caxambu, MG - v. CDRom, 2003. Disponível em:

http://professor.ufrgs.br/pedrofonseca/files/o desenvolvimento economico no primeir o_governo_de_vargas.pdf. Acesso em 30 de julho de 2020.

CASTRO, Antonio Barros de. A reconstrução industrial brasileira nos anos 90. Uma interpretação. Revista de Economia Política, vol. 21, n. 3, jul/set 2001, pp. 03-26. Disponível em: http://www.rep.org.br/pdf/83-1.pdf. Acesso em 06 de outubro de 2019.

CASTRO, Antonio Barros de. A Rica Fauna da Política Industrial e a sua Nova Fronteira. Disponível em:

https://edisciplinas.usp.br/pluginfile.php/1761025/mod_folder/content/0/CASTRO\%2C \%20A.B.\%20\%282002\%29.pdf?forcedownload=1. Acesso em 25 de novembro de 2019. DOI: https://doi.org/10.20396/rbi.v1i2.8648861.

LYRA, Flavio Tavares de. A Política Industrial Brasileira: Mudanças e Perspectivas. IPEA. Texto para discussão. N. 413. Maio 1996. Disponível em: http://repositorio.ipea.gov.br/bitstream/11058/1750/1/td_0413.pdf. Acesso em 20 de outubro de 2019.

MORAES, Rafael. O governo João Goulart e o empresariado industrial: uma abordagem alternativa da história econômica do período de 1961 a 1964 . Anais do $40^{\circ}$ Encontro Nacional de Economia ANPEC, Porto de Galinhas/PE. Disponível em: https://www.anpec.org.br/encontro/2012/inscricao/files I/i2-

2c5973b65db6447cd8a41acc012cb19e.pdf. Acesso em 22 de setembro de 2019.

OREIRO, José Luis; FEIJO, Carmem A.. Desindustrialização: conceituação, causas, efeitos e o caso brasileiro. Rev. Econ. Polit., São Paulo, v. 30, n. 2, p. 219-232, 2010. Disponível em: http://www.scielo.br/scielo.php?script=sci arttext\&pid=S010131572010000200003\&lng=en\&nrm=iso. Acesso em 25 de novembro de 2019. DOI: https://doi.org/10.1590/s0101-31572010000200003.

PRIZON, Ivan. Sistemas de inovação e a mudança econômica nos países de industrialização tardia: uma comparação dos esforços e desempenhos de Brasil e Coreia do Sul. Universidade Federal de Santa Maria, 2017. Disponível em: https://repositorio.ufsm.br/handle/1/12592?show=full. Acesso em 06 de outubro de 2019.

RODRIGUES, Carlos Henrique Lopes. Plano de Metas, PAEG e II PND: Análise e Desdobramentos. Anais do XI Congresso Brasileiro de História Econômica e 12a Conferência Internacional de História de Empresas, Vitória/ES. Disponível em: http://www.abphe.org.br/arquivos/2015 carlos henrique lopes rodrigues plano-demetas-paeg-e-ii-pnd-analise-e-desdobramentos.pdf. Acesso em 29 de setembro de 2019.

SUZIGAN, Wilson. A Indústria brasileira após uma década de estagnação: Questões para a Política Industrial. Anais das sextas jornadas anuales de economia. Montevidéu: Banco Central del Uruguay, 1991, pp. 02-50. Disponível em:

http://www.bvrie.gub.uy/local/File/JAE/1991/Suzigan.pdf. Acesso em 06 de outubro de 2019. 


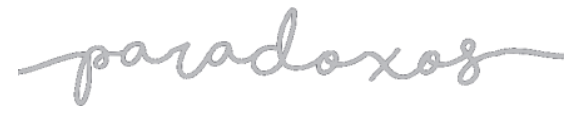

Desindustrialização e

investimento em tecnologia: a década de 1980 e seus reflexos nas décadas seguintes

HADDAD, 2021

SUZIGAN, Wilson. Política comercial e perspectivas da indústria brasileira. Revista Indicadores Econômicos, Porto Alegre, v. 20, n.4, 1993, p. 121-133. Disponível em: https://www.researchgate.net/profile/Wilson_Suzigan/publication/277038324_Politica comercial_e_perspectivas_da_industria_brasileira/links/56deda3808ae46f1e9a0ed19.pd f. Acesso em 20 de outubro de 2019.

SUZIGAN, Wilson; FURTADO, João. Política Industrial e Desenvolvimento. Revista de Economia Política, vol. 26, nº 2 (102), pp. 163-185 abril-junho/2006. DOI:

https://doi.org/10.1590/s0101-31572006000200001. 